\title{
Soluble form of ephrinB2 inhibits xenograft growth of squamous cell carcinoma of the head and neck
}

\author{
MACHIKO KIMURA ${ }^{1}$, YASUMASA KATO ${ }^{1,2}$, DAISUKE SANO ${ }^{1}$, KYOKO FUJITA $^{1}$, ATSUKO SAKAKIBARA ${ }^{1}$, \\ NORIO KONDO $^{1}$, YASUKAZU MIKAMI ${ }^{1}$ and MAMORU TSUKUDA ${ }^{1}$ \\ ${ }^{1}$ Department of Biology and Function in the Head and Neck, Yokohama City University Graduate School of Medicine, \\ 3-9 Fukuura, Kanazawa-ku, Yokohama 236-0004; ${ }^{2}$ Department of Biochemistry and Molecular Biology, \\ Kanagawa Dental College, 82 Inaoka-cho, Yokosuka 238-8580, Japan
}

Received July 24, 2008; Accepted September 8, 2008

DOI: 10.3892/ijo_00000154

\begin{abstract}
The ephB4-ephrinB2 system plays an important role in the interaction of tumor cells with endothelial cells (ECs). To assess the role of ephB4 in the in vivo growth of head and neck squamous cell carcinoma (HNSCC), we used ephrinB2-Fc, a fusion protein consisting of the extracellular domain of ephrin-B2 and the Fc portion of human $\operatorname{IgG} 1$, as the soluble ligand for ephB4. EphrinB2-Fc injection into HNSCC xenografted mice significantly suppressed xenograft growth, accompanied by a decrease in vessel cross-sectional area, but there was no change in vessel number. EphrinB2-Fc injection also induced the formation of mature blood vessels rich in $\alpha$-smooth muscle actin positive pericytes in the xenograft tissue. In vitro assays revealed that ephrinB2-Fc inhibited the proliferation of human umbilical vein ECs (HUVECs) but not tumor cells. Furthermore, real-time quantitative RT-PCR showed that ephrinB2-Fc down-regulated matrix metalloproteinase-2 mRNA expression in HUVECs and vascular endothelial growth factor-A in tumor cells. These data suggest that treatment with ephrinB2-Fc, the soluble ligand of ephB4, inhibited the growth of HNSCC through vessel maturation/stabilization, preventing leakiness and endothelial sprout formation.
\end{abstract}

Correspondence to: Dr Yasumasa Kato, Department of Biochemistry and Molecular Biology, Kanagawa Dental College, 82 Inaoka-cho, Yokosuka 238-8580, Japan

E-mail: yasumasa@kdcnet.ac.jp

Abbreviations: HN, head and neck; SCC, squamous cell carcinoma; siRNA, small interference RNA; HUVEC, human umbilical vein endothelial cell; EGF, epidermal growth factor; VEGF, vascular endothelial growth factor; RT-PCR, reverse transcription-polymerase chain reaction; ELISA, enzyme-linked immunosorbent assay; $\alpha$ SMA, $\alpha$-smooth muscle actin; EC, endothelial cells

Key words: EphB4, ephrinB2, head and neck squamous cell carcinoma

\section{Introduction}

Head and neck (HN) cancer is the sixth most frequent cancer worldwide, accounting for about $5 \%$ of all cancers, with an estimated 500,000-900,000 newly diagnosed individuals each year $(1,2)$. Squamous cell carcinoma (SCC) represents $90 \%$ of HN cancers (3). Despite significant advances in multidisciplinary treatments consisting of surgery, chemotherapy and radiotherapy to treat HNSCC, there has been little improvement in prognosis, due to the relapse of advanced locoregional tumors, distant metastases and secondary primary tumors. The development of new anti-tumor agents requires the identification of novel molecular targets.

Eph receptors and their ligands, the ephrins, are crucial in vasculogenesis and angiogenesis. The eph receptors can be divided into two subclasses, ephA (A1-A8, A10) the glycosylphosphatidylinositol-anchored type receptors, and ephB (B1-B4, B6) the transmembrane and tyrosine kinase type receptors. EphA and ephB receptors specifically bind to ephrinA (A1-A5) and ephrinB (B1-B3), respectively (4). EphB4 is a member of the largest known family of receptor protein tyrosine kinases, consisting of at least 14 distinct receptors and at least eight ligands (4). EphB4 and its ligand ephrinB2 are normally expressed on venous and arterial endothelial cells (ECs), respectively, and they are involved in vascular network assembly and vessel maturation (5-7).

Epithelial tumor cells have been shown to express ephB4, and high levels of expression are associated with advanced stage and poor prognosis of patients with uterine, endometrial, colorectal, and prostate cancer (8-12). In contrast to these clinical findings, ephB4 receptor activation has been reported to suppress tumorigenicity in breast cancer cells (13) and mouse melanoma cells (14). In addition, treatment of ECs with soluble ephB4 has been found to increase cell proliferation and in vitro invasion through matrigel $(15,16)$, suggesting that ephrinB2 on ECs are associated with tumor growth through angiogenesis. In HNSCC, down-regulation of ephB4 expression by small interfering RNA (siRNA) or antisense oligonucleotides has been shown to inhibit cell growth, migration and invasion in vitro, as well as growth in vivo (10). Thus, the exact role of the ephB4-ephrinB2 system in tumor tissue remains to be elucidated. We therefore assessed the role 
of ephB4 in tumor growth using ephrinB2-Fc, which activates ephB4 signaling and blocks ephrinB2 reverse-signaling.

\section{Materials and methods}

Reagents. Chimeric ephrinB2-Fc protein was purchased from R\&D Systems, Inc. (Abingdon, UK) and the control human IgG Fc fragment was from Jackson Laboratory (Bar Harbor, ME, USA). Monoclonal anti-Ki-67 antibody and monoclonal anti- $\alpha$-smooth muscle actin ( $\alpha$ SMA) for immunohistochemistry were from Dako (Carpenteria, CA, USA), and monoclonal anti-CD31 from BMA Biomedicals (Augst, Switzerland).

Cells and cell culture. Twelve human HNSCC cell lines were used: YCU-H891 (hypopharynx); YCU-M911 and YCU-M862 (oropharynx); YCU-L891 and KCC-L871 (larynx); YCUT891, KCC-T871, YCU-T892, KCC-T873, KCC-TCM902 and HSC-3 (tongue and oral floor); and KCC-MS871 (maxillary sinus). HSC-3 cells were obtained from the Japanese Cell Resources Bank (JCRB). Other cell lines were established in the Department of Otorhinolaryngology, Yokohama City University School of Medicine and the Research Institute, Kanagawa Cancer Center as described $(17,18)$. All cell lines were maintained in RPMI-1640 medium (Life Technologies Inc., Tokyo, Japan) supplemented with $10 \%$ fetal bovine serum (FBS), $2 \mathrm{mM}$ glutamine, $100 \mathrm{U} / \mathrm{ml}$ penicillin and $100 \mu \mathrm{g} / \mathrm{ml}$ streptomycin at $37^{\circ} \mathrm{C}$ in a humidified atmosphere of $5 \% \mathrm{CO}_{2}$ and $95 \%$ air. Human umbilical vein ECs (HUVECs) purchased from Cell Applications Inc. (San Diego, CA, USA) were maintained at $37^{\circ} \mathrm{C}$ in ECGM no. 211-500, a modified MCDB131 medium supplemented with FBS, epidermal growth factor (EGF), basic fibroblast growth factor and hydrocortisone optimized for HUVEC culture, excluding platelet-derived growth factor and vascular endothelial growth factor (VEGF), in humidified air containing $5 \% \mathrm{CO}_{2}$. HUVECs were used between passages three to five.

Cell proliferation assay. Cells were plated on 96-well culture plates at a density of $4 \times 10^{3}$ cells/well for tumor cell lines or $1 \times 10^{4}$ cells/well for HUVECs. The following day, the culture medium was changed to serum-free medium. The serumstarved cells were treated with various concentrations of ephrinB2-Fc or human IgG-Fc fragment (control) for $72 \mathrm{~h}$; the cells were treated with 3-(4,5-dimethylthiazol-2-yl)-2,5diphenyl tetrazolium bromide (MTT) reagent, and their absorbance was measured at $540 \mathrm{~nm}$ to determine relative viable cell numbers.

Quantitative reverse transcription-polymerase chain reaction $(R T-P C R)$. Cells were grown until nearly confluent in RPMI1640 supplemented with $10 \%$ FBS. Total RNA was isolated using Isogen ${ }^{\circledR}$ (Nippon Gene, Toyama, Japan), reverse-transcribed using AMV Reverse Transcriptase XL (Invitrogen, Carlsbad, CA, USA) and amplified by SYBR ${ }^{\circledR}$ Green ER qPCR super mix universal kit with specific primers (Table I) using a real-time PCR apparatus (Stratagene ${ }^{\circledR}$ MX3000P), according to the manufacturer's instructions. The amplification procedure consisted of one cycle of $50^{\circ} \mathrm{C}$ for $2 \min$ and $95^{\circ} \mathrm{C}$ for $10 \mathrm{~min}$, followed by 50 cycles of denaturation at $95^{\circ} \mathrm{C}$ for $15 \mathrm{sec}$ and annealing and extension at $60^{\circ} \mathrm{C}$ for $60 \mathrm{sec}$.
VEGF quantitation by enzyme-linked immunoabsorbent assay (ELISA). HNSCC cells were plated on 24-well culture plates at a density of $2.5-8.0 \times 10^{4}$ cells/well. On the following day, the culture medium was changed to serum-free medium and the cells were cultured overnight. The serum-starved cells were treated with $4 \mu \mathrm{g} / \mathrm{ml}$ ephrinB2-Fc or human IgG Fc fragment (control) for $48 \mathrm{~h}$, and the VEGF-A concentration in the conditioned medium was determined using a VEGF ELISA assay kit (R\&D Systems, Minneapolis, MN, USA) according to the manufacturer's protocol.

Mice and tumor xenograft model. Female immunodeficient $\mathrm{Balb} / \mathrm{c}$ nu/nu mice (6-week-old) were purchased from Oriental Yeast (Tokyo, Japan) and maintained at the Laboratory Animal Facility of Yokohama City University School of Medicine (Yokohama, Japan). All animal experiments were approved by the Animal Experiment Committee of Yokohama City University School of Medicine, and were in accordance with the guidelines for animal experiments.

YCU-H891 cells $\left(1 \times 10^{7}\right)$ were subcutaneously injected into the right flank of each mouse. Tumor growth was measured twice weekly, and tumor volume was calculated according to the following formula: $0.5 \mathrm{x} \mathrm{a} \mathrm{x} \mathrm{b}^{2}$, where ' $a$ ' and ' $b$ ' are the largest and smallest lengths of the tumor, respectively. On day 7 after cell implantation (tumor volumes, 50-100 $\mathrm{mm}^{3}$ ), the tumor-bearing animals were randomly divided into 2 groups ( $\mathrm{n}=6$ mice per group). EphrinB2-Fc or control-Fc $(1 \mathrm{mg} / \mathrm{kg}$ ) was intraperitoneally injected twice weekly for 4 weeks, and the animals were sacrificed under deep anesthesia. A portion of each tumor tissue was embedded in optimal-cuttingtemperature-embedding (OCT) medium (Tissue-Tek, Sakura Finetek, Tokyo, Japan) and snap-frozen in liquid nitrogen for histological analysis.

Immunohistochemical analysis. Frozen sections (5- $\mu$ m thick) of tumor tissues were fixed in cold acetone, blocked with $2 \%$ goat serum and $1 \%$ bovine serum albumin in phosphatebuffered saline, and stained with the appropriate primary antibodies (Ki-67, 1:50 dilution ratio; CD-31, 1:400; $\alpha$ SMA, 1:50 dilution). Tissue samples were further treated with biotin-conjugated secondary antibody, avidin-conjugated peroxidase, and 3,3'-diaminobenzidine substrate (Vector Laboratories, Inc., Burlingame, CA, USA). Seven randomly selected fields in each sample were examined by lightmicroscope at x100 (middle power field, MPF) or x400 (high power field, HPF) magnification. Apoptosis was evaluated in frozen sections using the In situ Apoptosis Detection Kit (Takara Bio Inc., Shiga, Japan), according to the manufacturer's instructions.

Statistical analysis. Groups were compared using paired Student's t-tests. A $p<0.05$ was considered statistically significant.

\section{Results}

Inhibition of HNSCC growth by ephrinB2-Fc treatment in vivo. To clarify the role of ephB4 and ephrinB2 in the in vivo growth of HNSCC, mRNA levels of ephB4 and ephrinB2 in 11 HNSCC cell lines were assayed by quantitative RT-PCR. 
Table I. PCR primers.

Gene

Sequence $\left(5^{\prime} \rightarrow 3^{\prime}\right)$

Fragment size (bp)

EphB4

Forward: TTCGGCCAGGAACATCACAG

Reverse: CCGATGAGATACTGTCCGTG

EphrinB2

Forward: GGAAGAAGTTCGACAACAAGTCC

182

Reverse: TTCAGCAAGAGGACCACCAGCGT

VEGF-A

Forward: GCTACTGCCATCCAATCGAG

Reverse: TGGTGATGTTGGACTCCTCA

164

MT1-MMP

Forward: GGGTACTCTGTGGTAGGG

Reverse: CTCCCGCACTGCTGTTTGTT

MMP2

Forward: TCGCACACCACATCTTTC

Reverse: TGGGCAACAAATATGAGAGCTG

68

GAPDH

Forward: CACCCAGAAGACTGTGGATG

Reverse: AGGCCATGCCAGTGAGCTTC

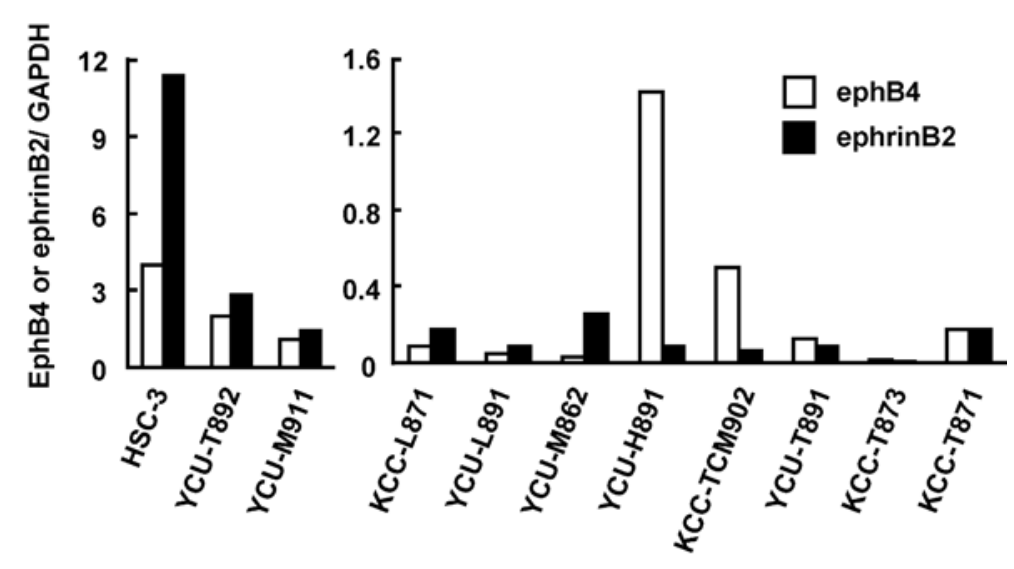

Figure 1. EphB4 and ephrinB2 mRNA expression in HNSCC cell lines. EphB4 and ephrinB2 mRNA expression was determined by real-time RT-PCR in 11 HNSCC cell lines. The level of each mRNA was normalized relative to GAPDH mRNA.

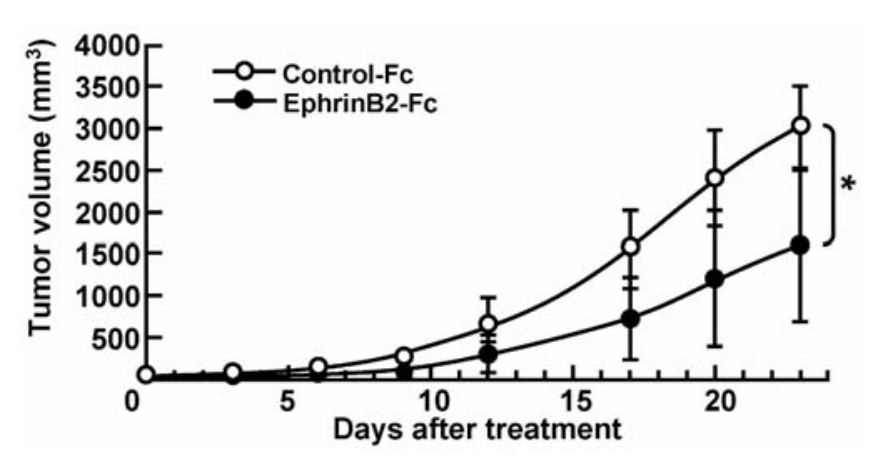

Figure 2. EphrinB2-Fc inhibition of the growth of YCU-H891 xenografts in vivo. YCU-H891 cells were subcutaneously injected into the back skin of Balbc nu/nu mice. Tumor-bearing mice were treated with $1 \mathrm{mg} / \mathrm{kg}$ ephrinB2Fc $(\bullet)$ or control-Fc $(\bullet)$ twice weekly, and tumor volumes were measured every 3 or 5 days. Error bars, $\mathrm{SD}(\mathrm{n}=6) ;{ }^{*} \mathrm{p}<0.05$ (Student's t-test).

Although expression levels varied, all cell lines expressed mRNA encoding ephB4 and ephrinB2 (Fig. 1).

We then evaluated role of ephB4-ephrinB2 system on the growth of HNSCC xenograft in nude mice using chimeric
ephrinB2-Fc. Treatment with ephrinB2-Fc significantly decreased tumor growth compared with control-Fc (Fig. 2). Immunohistochemical analysis of the tumor sections showed that ephrinB2-Fc administration reduced the Ki-67 labeling index $34 \%$ (Fig. 3A and B), but had no effect on apoptosis (by TUNEL assay) (Fig. 3A) or CD31 positive vascular density (Fig. 4A and B). Interestingly, ephrinB2-Fc significantly reduced the cross sectional area of CD31 positive vessels (Fig. 4A and C) and significantly increased the ratio of aSMA positivity compared with mice treated with control-Fc (Fig. 4A and D). These findings indicated that administration of ephrinB2-Fc induced pericyte-rich maturation without affecting the formation of new blood vessels.

Effect of ephrinB2-Fc treatment on proliferation of HNSCC and HUVECs in vitro. To understand the mechanism by which ephrinB2-Fc reduced the growth reduction of xenografts, we treated HNSCC cells and HUVECs with ephrinB2-Fc in vitro. Treatment with ephrinB2-Fc reduced the growth rate of HUVECs (Fig. 5A), but not of 3 HNSCC cell lines (Fig. 5B), suggesting that ephrinB2-Fc reduces xenograft growth by 
A
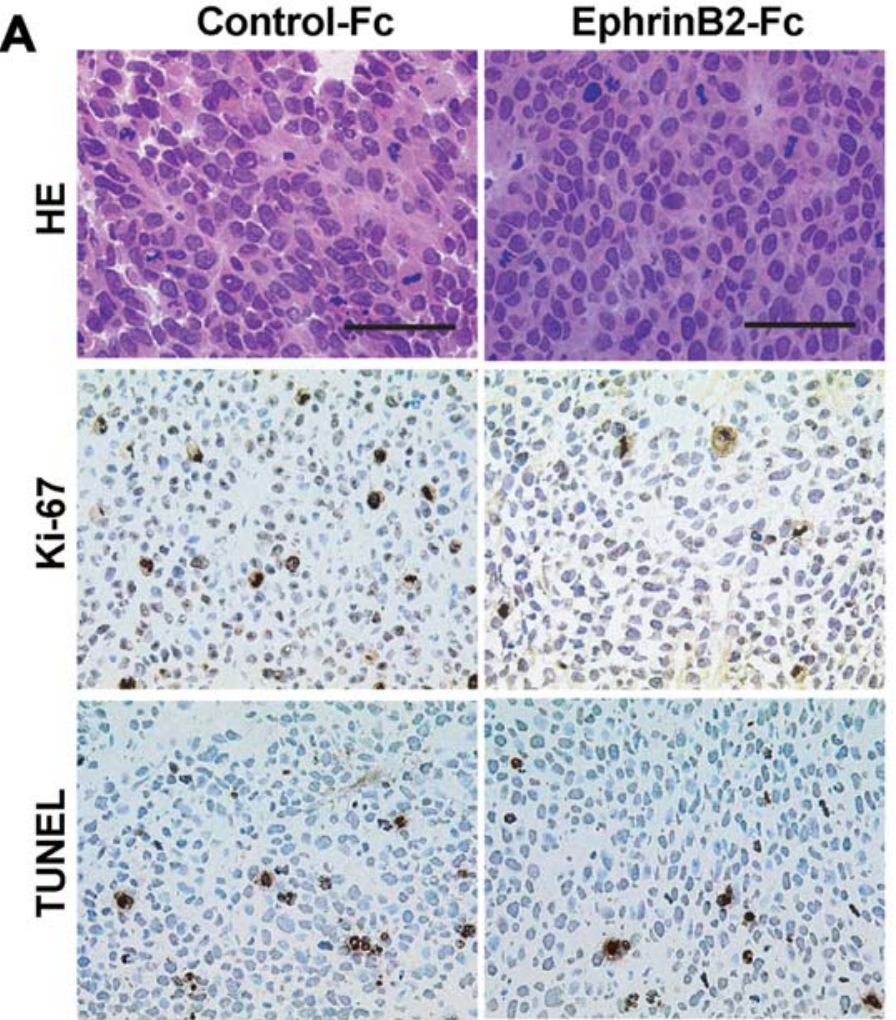

EphrinB2-Fc

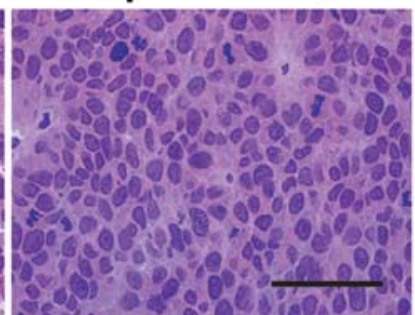

C

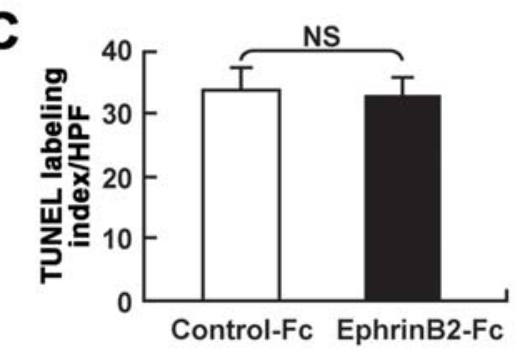

Figure 3. Administration of ephrinB2-Fc inhibits proliferation but not apoptosis in YCU-H891 xenografts. Tumor-bearing mice were sacrificed under overdose anesthesia. Frozen tumor tissues were sectioned at $5 \mu \mathrm{m}$ and analyzed by HE staining (x400) (A, upper panels), immunocytochemistry using antiKi-67 antibody (x400) (A, middle panels; B), and TUNEL to detect apoptotic cells (x400) (A, lower panels; C). Bar, $50 \mu$ m; error bars, SD (n=6); ${ }^{*} \mathrm{p}<0.05$ (Student's t-test).
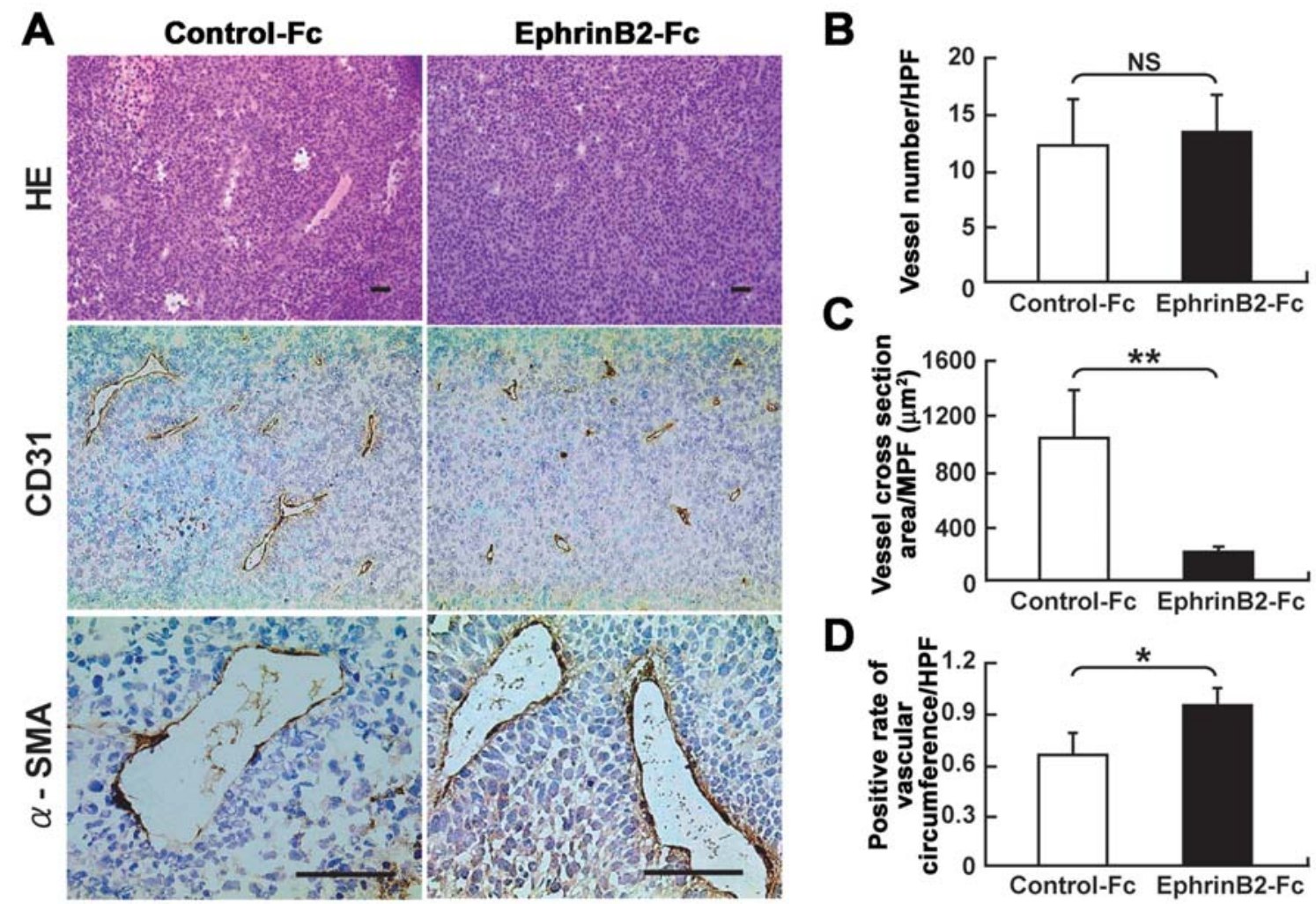

Figure 4. Administration of ephrinB2-Fc decreases vessel cross sectional area but not vessel density in YCU-H891 xenografts. Tumor-bearing mice were sacrificed, and frozen tumor tissues were sectioned at $5 \mu \mathrm{m}$ and stained with HE (A, upper panels) and analyzed by immunocytochemistry using anti-CD31 antibody and anti- $\alpha$ SMA antibody to detect ECs and pericytes, respectively. MPF, middle power field (x400); HPF, high power field (x100); Bar, $50 \mu$ m; error bar, $\mathrm{SD}(\mathrm{n}=6) ;{ }^{*} \mathrm{p}<0.05 ;{ }^{* *} \mathrm{p}<0.001$ (Student's t-test). 
A

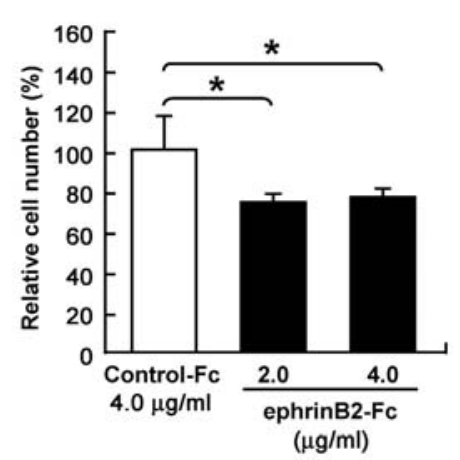

B

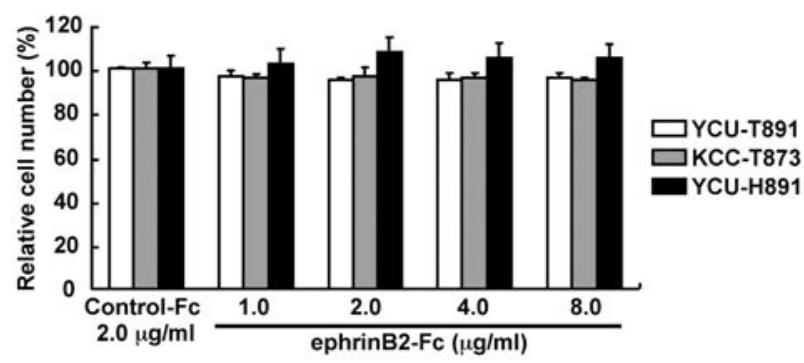

Figure 5. EphrinB2-Fc does not affect proliferation of HNSCC cell lines but reduces proliferation of HUVECs. HUVECs ( $1 \times 10^{4}$ cells/well) or tumor cells $\left(4 \times 10^{3}\right.$ cells/well) were inoculated into 96 -well culture plates, incubated overnight, serum-starved, and treated with ephrinB2-Fc or control-Fc for 3 days. Relative viability was determined following MTT incorporation. A, HUVECs; B, YCU-H891 cells; error bars, SD (n=4); " $\mathrm{p}<0.05$ (Student's t-test).

inhibiting the maturation of tumor vessels.

EphrinB2 reverse-signaling in HUVECs. To examine role of reverse-signaling in HUVECs, ephrinB2 signaling in HUVECs was blocked by adding ephrinB2-Fc. Quantitative RT-PCR analysis revealed that ephrinB2-Fc downregulated the steady state levels of VEGF-A, MT1-MMP and MMP 2 mRNAs to $34.8,28.3$ and $28.7 \%$, respectively, of their levels in the absence of ephrinB2-Fc (Fig. 6). The reduction in MMP2 mRNA expression was statistically significant.

EphB4 signaling in HNSCC cells. When tested the effect of ephrinB2-Fc on VEGF-A secretion in YCU-H891 cells in vitro, we found that ephrinB2-Fc reduced secretion $20 \%$ (Fig. 7). To determine whether this reduction was restricted to YCU-H891 cells, we tested 6 additional HNSCC cell lines. In three of these cell lines, ephrinB2-Fc decreased VEGF-A secretion significantly (Fig. 7), suggesting that ephrinB2-Fc treatment reduces tumor growth by inhibiting ephrinB2 signaling leading to maturation of early stage cells.

\section{Discussion}

In the present study, we have shown here that treatment with ephrinB2-Fc, which activates ephB4 signaling but suppresses reverse-signaling of ephrinB2, inhibits the growth of HNSCC tumor xenografts in vitro without affecting the growth of HNSCC cell lines. EphrinB2-Fc significantly reduced the Ki-67 labeling index but had no effect on apoptotic index, suggesting that ephrinB2-Fc affects vessel formation rather
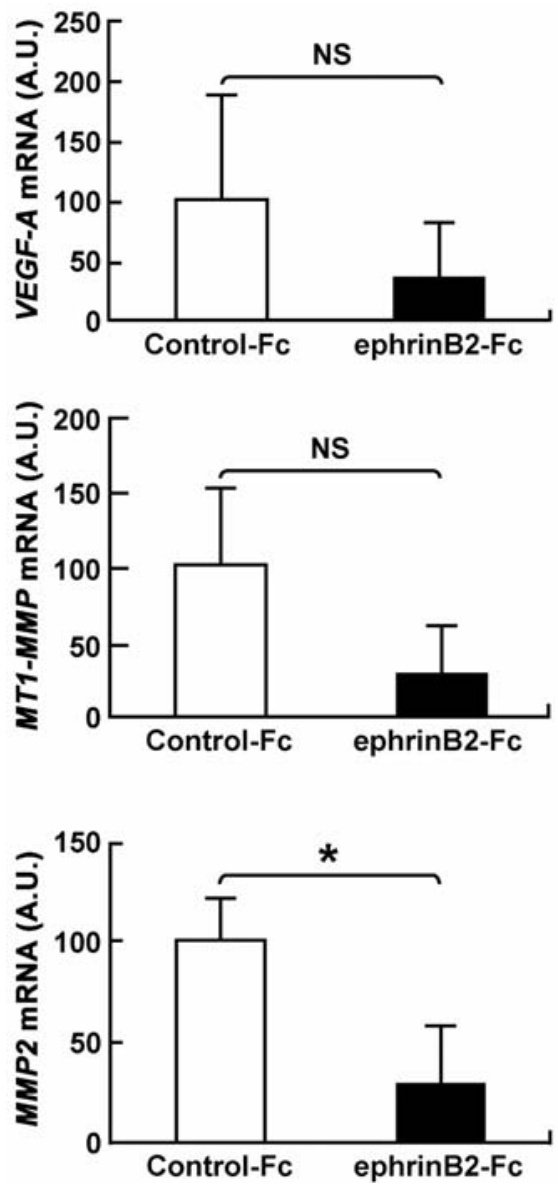

Figure 6. Expression of angiogenesis-related factors in HUVECs. Cells were treated with ephrinB2-Fc or control-Fc for $24 \mathrm{~h}$. Total RNA was purified and reverse-transcribed. Expression of angiogenesis-related factor mRNAs (VEGF-A, MT1-MMP, MMP2) in HUVECs was examined by quantitative PCR. The results shown are representative of three independent experiments. Error bars, SD ( $\mathrm{n}=3) ;{ }^{*} \mathrm{p}<0.05$ (Student's t-test).

than acting directly on tumor proliferation. Treatment with ephrinB2-Fc induced formation of matured narrow vessels, whereas treatment with control-Fc alone led to xenograft vessels with unstable structures and wide cross-sectional areas. MTT assays showed that ephrinB2-Fc reduced the cell proliferation of HUVECs compared with cells treated with control human IgG. Furthermore, ephrinB2-Fc significantly reduced the steady state levels of expression of MMP2 mRNA, a marker of angiogenesis-related gene expression. Similarly, activation of ephB4 by ephrinB2-Fc was found to inhibit the VEGF-A-induced migration of human microvascular endothelial cells, whereas activation of ephrinB2-reverse signaling by ephB4-Fc did not (19). We also found that $\alpha$ SMApositive pericytes were closely associated with endothelial cells in ephrinB2-Fc-administered xenograft tissue. Pericyte aSMA expression is a common feature of tumor tissue, and pericytes are tightly associated with endothelial cells in normal tissue but loosely in tumor tissue (20). Therefore, coverage status of the vessels with pericytes ( $\alpha$ SMA-positive cells in tumor tissue) is regarded as a parameter for the maturation of blood vessels. EphrinB2-Fc administration increased aSMA expression in unstable large vessels, suggesting that ephrinB2-Fc induced vessel maturation in 

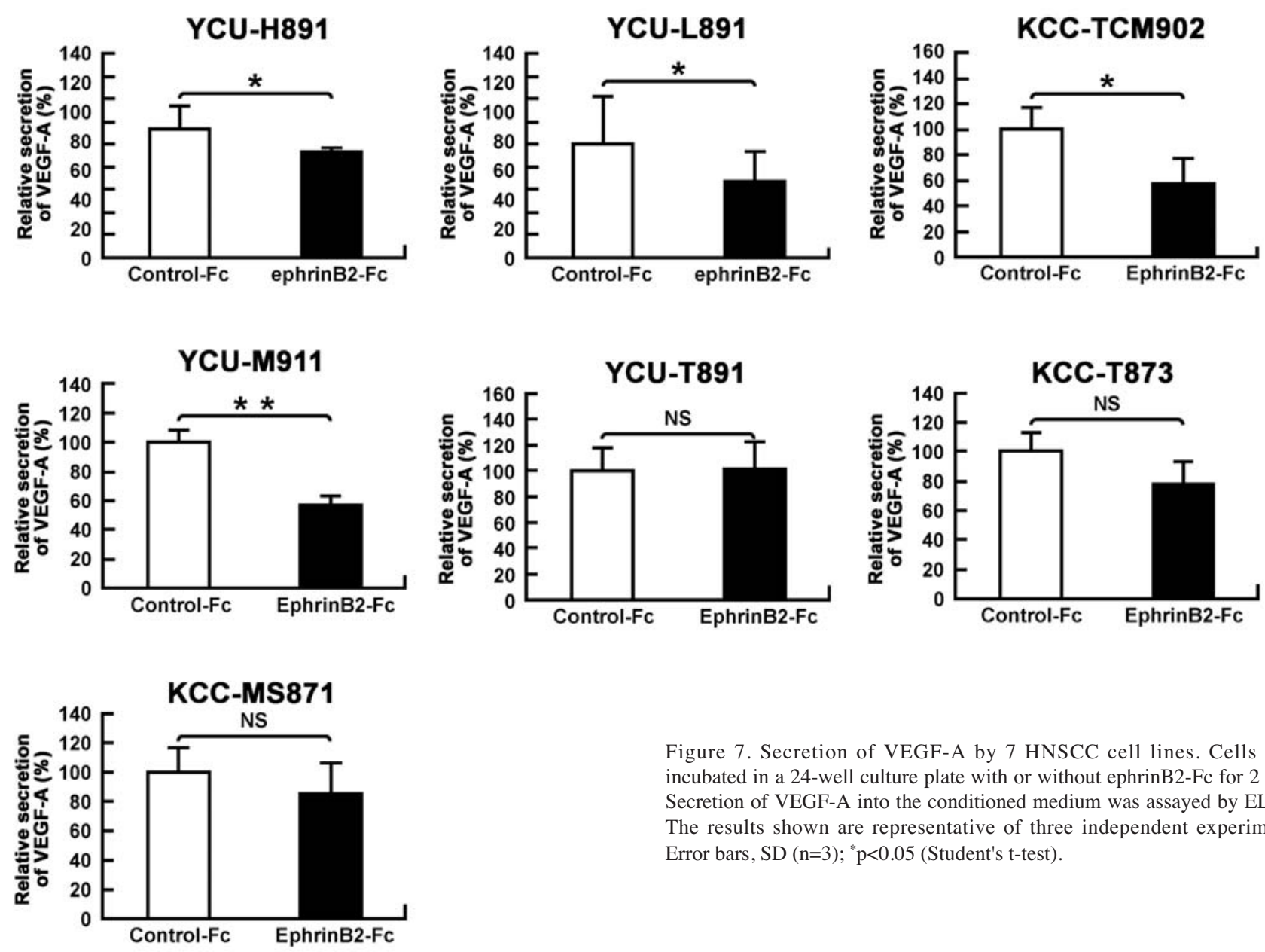

Figure 7. Secretion of VEGF-A by 7 HNSCC cell lines. Cells were incubated in a 24-well culture plate with or without ephrinB2-Fc for 2 days Secretion of VEGF-A into the conditioned medium was assayed by ELISA. The results shown are representative of three independent experiments. Error bars, $\mathrm{SD}(\mathrm{n}=3) ;{ }^{*} \mathrm{p}<0.05$ (Student's t-test).

HNSCC. Induction of blood vessel maturation by introduction of angiopoietin-1 expressing vector has been reported to reduce the growth in A431 cell (originated from uterine carcinoma)-xenografted models (21). Because maturation of blood vessels rich in pericytes increases stability and prevents leakiness, failure of endothelial sprout formation and leakiness are thought to inhibit angiogenesis and nutrition and oxygen supply in tumor tissue. Although vessel density was not altered, longer treatment with ephrinB2-Fc may reduce vessel density because stable vessels prevent sprout formation.

Although ephrinB2-Fc has been shown to inhibit the proliferation and/or migration of HUVECs and other endothelial cells (ECs) in vitro and in vivo $(19,21-24)$, ephrinB2-Fc has also been shown to induce the proliferation and migration of ECs $(15,25)$. These discrepancies may be due to the specific cell type of ECs (i.e., umbilical vein versus microvascular) or the balance between ephB4 signaling and ephrinB2 reversesignaling. In assessing the induction of angiogenenesis by ephrinB2-Fc using mouse corneal assay in vivo, ephrinB2-Fc was found to be a chemoattractant, suggesting that its chemotactic activity depended on its concentration gradient (15). In our model, however, ephrinB2-Fc inhibited angiogenesis, suggesting that ephB4-ephrinB2 signaling may depend on cell type or microenvironment, including levels of growth factors such as VEGF-A (19).

Most patients with advanced stage disease show high levels of ephB4 expression, whereas the ephB4 suppression of tumorigenicity was strongly associated with EGF receptor signaling in HNSCC cell lines (10). Although EGF receptor is frequently over-expressed in HNSCC (26-28), our survey of 17 HNSCC cell lines showed strong expression in 3, moderate expression in 5 and slight expression in 9 (18). In addition, YCU-H891 cells, which were used in this study, expressed very low levels of EGF receptor protein. Thus, the presence of EGF and/or VEGF may alter the effects of ephB4/ephrinB2 signaling on the growth of HNSCC cells. Similarly, two different ligand-signals have been reported to orchestrate other cellular functions: e.g., angiopoietin-2 antagonizes the function of angiopoietin- 1 in the absence of VEGF but facilitates vascular sprouting in the presence of VEGF (29); VEGF-A-induced proliferation and migration of ECs are suppressed by ephrinB2-Fc through inhibition of Ras/MAPK signaling cascades (22).

Proteolytic degradation of basement membrane and migration of ECs are involved in endothelial sprout formation, the first step of angiogenesis (30-34). MMP2 and the MT1MMP system are extremely important for the regulation of angiogenesis via VEGF-A (35-38). We found that activation of ephB4 by ephrinB2-Fc in vitro inhibited VEGF-A production not only in YCU-H891 cells, but in the other six cell lines examined. Moreover, this down-regulation was also observed in the xenograft model. Thus, our findings suggest that ephrinB2-Fc suppresses tumor growth through activation of 
ephB4, reducing VEGF-A expression in tumor cells and concomitantly inhibiting reverse-signaling of ephrinB2 in ECs, leading to the maturation of blood vessels. Although most patients with advanced stage disease showed ephB4 expression, the number of patients surveyed was limited, and little was known regarding their clinicopathological condition (10). In addition, this study showed that ephB4 had no effect on EGFR-negative patients, is similar to our model. Therefore, a larger number of patients should be surveyed to determine the exact role of ephB4-ephrinB2 signaling on HNSCC.

In conclusion, we showed that ephrinB2-Fc treatment reduced the growth of xenografts by decreasing EC production of VEGF and by reducing vessel density, as well as by increasing vessel maturation. Therefore, treatment with ephrinB2-Fc, the soluble ligand for ephB4, may be an efficient therapeutic strategy for patients with advanced HNSCC.

\section{References}

1. Reuter CW, Morgan MA and Eckardt A: Targeting EGF-receptorsignalling in squamous cell carcinomas of the head and neck. Br J Cancer 96: 408-416, 2007.

2. Sankaranarayanan R, Masuyer E, Swaminathan R, Ferlay J and Whelan S: Head and neck cancer: a global perspective on epidemiology and prognosis. Anticancer Res 18: 4779-4786, 1998.

3. Rogers SJ, Harrington KJ, Rhys-Evans P, O-Charoenrat P and Eccles SA: Biological significance of c-erbB family oncogenes in head and neck cancer. Cancer Metastasis Rev 24: 47-69, 2005.

4. Gale NW, Holland SJ, Valenzuela DM, et al: Eph receptors and ligands comprise two major specificity subclasses and are reciprocally compartmentalized during embryogenesis. Neuron 17: 9-19, 1996

5. Adams RH, Wilkinson GA, Weiss C, et al: Roles of ephrinB ligands and EphB receptors in cardiovascular development: demarcation of arterial/venous domains, vascular morphogenesis, and sprouting angiogenesis. Genes Dev 13: 295-306, 1999.

6. Gerety SS, Wang HU, Chen ZF and Anderson DJ: Symmetrical mutant phenotypes of the receptor EphB4 and its specific transmembrane ligand ephrin-B2 in cardiovascular development. Mol Cell 4: 403-414, 1999.

7. Wang HU, Chen ZF and Anderson DJ: Molecular distinction and angiogenic interaction between embryonic arteries and veins revealed by ephrin-B2 and its receptor Eph-B4. Cell 93: 741-753, 1998.

8. Alam SM, Fujimoto J, Jahan I, Sato E and Tamaya T: Overexpression of ephrinB2 and EphB4 in tumor advancement of uterine endometrial cancers. Ann Oncol 18: 485-490, 2007.

9. Davalos V, Dopeso H, Castano J, et al: EPHB4 and survival of colorectal cancer patients. Cancer Res 66: 8943-8948, 2006.

10. Masood R, Kumar SR, Sinha UK, et al: EphB4 provides survival advantage to squamous cell carcinoma of the head and neck. Int J Cancer 119: 1236-1248, 2006.

11. Takai N, Ueda T, Nishida M, Nasu K and Miyakawa I: The relationship between oncogene expression and clinical outcome in endometrial carcinoma. Curr Cancer Drug Targets 4: 511-520, 2004.

12. Xia G, Kumar SR, Masood R, et al: EphB4 expression and biological significance in prostate cancer. Cancer Res 65 : 4623-4632, 2005.

13. Noren NK, Foos G, Hauser CA and Pasquale EB: The EphB4 receptor suppresses breast cancer cell tumorigenicity through an Abl-Crk pathway. Nat Cell Biol 8: 815-825, 2006.

14. Huang X, Yamada Y, Kidoya H, et al: EphB4 overexpression in B16 melanoma cells affects arterial-venous patterning in tumor angiogenesis. Cancer Res 67: 9800-9808, 2007.

15. Maekawa H, Oike Y, Kanda S, et al: Ephrin-B2 induces migration of endothelial cells through the phosphatidylinositol-3 kinase pathway and promotes angiogenesis in adult vasculature. Arterioscler Thromb Vasc Biol 23: 2008-2014, 2003.

16. Steinle JJ, Meininger CJ, Chowdhury U, Wu G and Granger HJ: Role of ephrin B2 in human retinal endothelial cell proliferation and migration. Cell Signal 15: 1011-1017, 2003.
17. Nishimura G, Yanoma S, Satake K, et al: An experimental model of tumor dormancy therapy for advanced head and neck carcinoma. Jpn J Cancer Res 91: 1199-1203, 2000.

18. Taguchi T, Tsukuda M, Imagawa-Ishiguro $\mathrm{Y}$, Kato $\mathrm{Y}$ and Sano D: Involvement of EGFR in the response of squamous cell carcinoma of the head and neck cell lines to gefitinib. Oncol Rep 19: 65-71, 2008.

19. Sturz A, Bader B, Thierauch KH and Glienke J: EphB4 signaling is capable of mediating ephrinB2-induced inhibition of cell migration. Biochem Biophys Res Commun 313: 80-88, 2004.

20. Morikawa S, Baluk P, Kaidoh T, Haskell A, Jain RK and McDonald DM: Abnormalities in pericytes on blood vessels and endothelial sprouts in tumors. Am J Pathol 160: 985-1000, 2002.

21. Hawighorst T, Skobe M, Streit M, et al: Activation of the tie2 receptor by angiopoietin- 1 enhances tumor vessel maturation and impairs squamous cell carcinoma growth. Am J Pathol 160: 1381-1392, 2002.

22. Kim I, Ryu YS, Kwak HJ, et al: EphB ligand, ephrinB2, suppresses the VEGF- and angiopoietin 1-induced Ras/mitogenactivated protein kinase pathway in venous endothelial cells. FASEB J 16: 1126-1128, 2002.

23. Oike Y, Ito Y, Hamada K, et al: Regulation of vasculogenesis and angiogenesis by EphB/ephrin-B2 signaling between endothelial cells and surrounding mesenchymal cells. Blood 100: 1326-1333, 2002.

24. Zhang XQ, Takakura N, Oike Y, Inada T, Gale NW, Yancopoulos GD and Suda T: Stromal cells expressing ephrinB2 promote the growth and sprouting of ephrin-B2(+) endothelial cells. Blood 98: 1028-1037, 2001.

25. Steinle JJ, Meininger CJ, Forough R, Wu G, Wu MH and Granger HJ: Eph B4 receptor signaling mediates endothelial cell migration and proliferation via the phosphatidylinositol 3kinase pathway. J Biol Chem 277: 43830-43835, 2002.

26. Dassonville O, Formento JL, Francoual M, et al: Expression of epidermal growth factor receptor and survival in upper aerodigestive tract cancer. J Clin Oncol 11: 1873-1878, 1993.

27. Eisbruch A, Blick M, Lee JS, Sacks PG and Gutterman J: Analysis of the epidermal growth factor receptor gene in fresh human head and neck tumors. Cancer Res 47: 3603-3605, 1987.

28. Santini J, Formento JL, Francoual M, Milano G, Schneider M, Dassonville O and Demard F: Characterization, quantification, and potential clinical value of the epidermal growth factor receptor in head and neck squamous cell carcinomas. Head Neck 13: 132-139, 1991.

29. Yancopoulos GD, Davis S, Gale NW, Rudge JS, Wiegand SJ and Holash J: Vascular-specific growth factors and blood vessel formation. Nature 407: 242-248, 2000.

30. Ben-Yosef Y, Lahat N, Shapiro S, Bitterman H and Miller A: Regulation of endothelial matrix metalloproteinase-2 by hypoxia/ reoxygenation. Circ Res 90: 784-791, 2002.

31. Galvez BG, Matias-Roman S, Albar JP, Sanchez-Madrid F and Arroyo AG: Membrane type 1-matrix metalloproteinase is activated during migration of human endothelial cells and modulates endothelial motility and matrix remodeling. J Biol Chem 276: 37491-37500, 2001.

32. Jain RK: Molecular regulation of vessel maturation. Nat Med 9: 685-693, 2003.

33. Oh J, Seo DW, Diaz T, et al: Tissue inhibitors of metalloproteinase 2 inhibits endothelial cell migration through increased expression of RECK. Cancer Res 64: 9062-9069, 2004.

34. Ottino P, Finley J, Rojo E, Ottlecz A, Lambrou GN, Bazan HE and Bazan NG: Hypoxia activates matrix metalloproteinase expression and the VEGF system in monkey choroid-retinal endothelial cells: Involvement of cytosolic phospholipase A2 activity. Mol Vis 10: 341-350, 2004.

35. Berglin L, Sarman S, van der Ploeg I, et al: Reduced choroidal neovascular membrane formation in matrix metalloproteinase-2deficient mice. Invest Ophthalmol Vis Sci 44: 403-408, 2003.

36. Chun TH, Sabeh F, Ota I, et al: MT1-MMP-dependent neovessel formation within the confines of the three-dimensional extracellular matrix. J Cell Biol 167: 757-767, 2004.

37. Hiratsuka S, Maru Y, Okada A, Seiki M, Noda T and Shibuya M: Involvement of Flt-1 tyrosine kinase (vascular endothelial growth factor receptor-1) in pathological angiogenesis. Cancer Res 61: 1207-1213, 2001.

38. Sounni NE, Devy L, Hajitou A, et al: MT1-MMP expression promotes tumor growth and angiogenesis through an upregulation of vascular endothelial growth factor expression. FASEB J 16: 555-564, 2002 